Vol. VIII, No. 2, Agustus 2015

P-ISSN: $1979-858 \mathrm{X}$

Halaman 97 - 110

\title{
PENGARUH SISTEM PENGUKURAN KINERJA NON-FINANSIAL TERHADAP KINERJA ANGGOTA KEPOLISIAN, JOB TENSION SEBAGAI FAKTOR PEMEDIASI
}

\author{
Sri Mawarni \\ STIE Prasetiya Mandiri Lampung
}

\begin{abstract}
This research aims to explain the effect of non-financial performance measurement system, job tension, on peformance of members of the police. In order to achieve the objective of the study, this research is conducted at the police institution in Lampung Province. Based on 160 usable data, we analyzed using Structural Equation Model, in particularly SmartPLS. The result of the study indicates that non-financial performance measurement enable to decrease job tension that it will impact on the improvement of individual performance. However, based on further examination whether direct or indirect is more effective to improve a member of police performance, we found that direct relationship between Non-Financial Performance Measurement System and Employee Performance rather than indirect effect through job tension. This study implies that non-financial performance measurement can improve the member of police institution performance.
\end{abstract}

Keyword: Non-Financial Performance Measurement System, Job Tension and Employee Performance.

ABSTRAK: Penelitian ini bertujuan untuk menjelaskan pengaruh sistem pengukuran kinerja non-keuangan, ketegangan pekerjaan, pada peformance dari anggota polisi. Dalam rangka mencapai tujuan penelitian, penelitian ini dilakukan di institusi kepolisian di Provinsi Lampung. Berdasarkan 160 data yang dapat digunakan, penulis menggunakan Structural Equation Model, khususnya SmartPLS. Hasil penelitian menunjukkan bahwa pengukuran kinerja non-keuangan memungkinkan untuk menurunkan ketegangan pekerjaan yang akan berdampak pada peningkatan kinerja individu. Namun, berdasarkan pemeriksaan lebih lanjut apakah langsung atau tidak langsung lebih efektif untuk meningkatkan anggota dari kinerja polisi, penulis menemukan bahwa hubungan langsung antara Kinerja Non-Keuangan Sistem Pengukuran dan Kinerja Karyawan daripada pengaruh tidak langsung melalui ketegangan pekerjaan. Studi ini menunjukkan bahwa pengukuran kinerja non-keuangan dapat meningkatkan kinerja anggota lembaga kepolisian.

Keyword: Sistem Pengukuran Kinerja Non Keuangan, Tensi Kerja, Dan Kinerja Pegawai

\footnotetext{
${ }^{1}$ Draft pertama: 18 Agustus 2015; Revisi: 12 September 2015; Diterima: 16 Oktober 2015

Penulis dapat dikontak melalui: nani.mawarni77@gmail.com
} 


\section{PENDAHULUAN}

Sistem pengukuran kinerja diharapkan dapat memberikan panduan yang jelas terhadap tujuan yang hendak dicapai individu dalam mendukung tujuan keseluruhan organisasi. Hal itu terjadi karena sistem pengukuran kinerja mempunyai fungsi untuk mengevaluasi pencapaian tujuan organisasi (Chenhall, 2005, Kaplan and Norton, 1992, Kaplan and Norton, 1996). Kim and Larry (1998) mengungkapkan sistem pengukuran kinerja merupakan frekuensi pengukuran kinerja pada manajer dalam unit oganisasi yang dipimpin mengenai kualitas dalam aktivitas operasional perusahaan. Banyak kemajuan dalam pengembangan pengukuran kinerja yang bertujuan untuk menyeimbangkan pengukuran yang berorientasi pada aspek keuangan yaitu pengukuran kinerja nonkeuangan.

Pengukuran kinerja non-keuangan dipercaya bisa digunakan untuk melengkapi indikasi pengukuran kinerja keuangan jangka pendek dan sebagai indikator kinerja jangka panjang (Kaplan dan Norton, 1996). Lau and Sholihin (2005) berargumen penggunaan pengukuran non-keuangan jangka panjang cenderung menghasilkan perilaku karyawan yang lebih positif dari pada yang dihasilkan oleh penggunaan pengukuran keuangan jangka pendek. Pengukuran kinerja non-finansial memiliki peran yang sangat penting bagi organisasi publik karena pengukuran kinerja tersebut dapat membantu pembuat keputusan dalam menilai bagaimana kinerja individu dalam organisasi pemerintah dapat memberikan kualitas pelayanan kepada publik.

Salah satu contoh penelitian pengukuran kinerja di sektor publik khususnya di kepolisian di UK dilakukan oleh Sholihin dan Pike (2010) dimana mereka menemukan bahwa pengukuran kinerja dapat meningkatkan keadilan prosedural dan komitmen organisasi. Mengembangkan penelitian mereka, penelitian ini juga difokuskan pada sektor publik khususnya institusi kepolisian karena institusi kepolisian merupakan pelayanan publik yang bergantung dari dedikasi para anggotanya dan sering menjadi sorotan publik. Saat ini institusi kepolisian sedang berusaha untuk memperbaiki citranya dimata masyarakat dengan menjadi lebih humanis dan berusaha menumbuhkan kembali kepercayaan masyarakat pada institusi ini. Di kepolisian, pengukuran keuangan dan nonkeuangan berperan penting dalam pengelolaan kinerja polisi (Chatterton et al. 1996 and Home Office, 2004 dalam Sholihin and Pike, 2010).

Sistem pengukuran kinerja dapat memberikan pemahaman yang jelas dengan menyediakan informasi kinerja yang dapat meningkatkan pemahaman seorang karyawan mengenai kinerja, dampak suatu tindakan, dan hubungan antar bagian yang berbeda dalam operasional perusahaan (James and Hoque, 2000, dan Hoque et al, 2001). Lawler (1992) berargumen bahwa informasi tentang misi suatu organisasi dan kinerja dibutuhkan oleh individu untuk mengetahui bagaimana mereka harus bertindak. Bowen and Lawler (1992) berpendapat bahwa akses informasi mengenai organisasi memungkinkan seorang individu untuk mengetahui dengan jelas dan memberikan pemahaman bagaiman peran mereka dalam perusahaan.

Beberapa penelitian sebelumnya melihat bahwa pengukuran kinerja dapat memberikan panduan yang jelas bagi anggota organisasi untuk melaksanakan pekerjaan seperti yang telah dijelaskan dalam tupoksi masing-masing karyawan. Sehingga setiap individu mempunyai role clarity yang jelas atau tupoksinya. Hall (2008) menemukan bahwa ada hubungan positif antara sistem pengukuran kinerja dengan role clarity. Aspek pertama pengukuran kinerja dapat mengurangi job tension dilihat dari kejelasan individu dari pekerjaan tersebut diatas sehingga dapat mengurangi role ambiguity. Burney et al (2009) mengatakan bahwa sistem pengukuran kinerja dapat mengurangi role ambiguity dan (Burney and widener., 2007) yang akhirnya dapat mengurangi job tension. 
Tekanan kerja yang dirasakan oleh karyawan di lingkungan kerja akan mengakibatkan job tension seperti stres dan sebagainya yang akhirnya akan berpengaruh pada kinerja karyawan. Dalam penelitian yang dilakukan oleh Lusch and Serpkenci (1990) menemukan bahwa pengukuran tekanan kerja akan menurunkan kinerja. Shields et al (200o) menemukan terdapat korelasi negatif antara job related tension dan kinerja. Penelitian yang dilakukan oleh Pool (2000) menyatakan bahwa ada korelasi antara job tension dan kinerja, tingginya tekanan kerja akan menurunkan kadar kepuasan kerja, kinerja dan komitmen kerja.

Berdasarkan kepada pemahaman diatas, kami berargumen bahwa sistem pengukuran kinerja non-finansial dapat membantu mengurangi job tension. Berkurangnya job tension akan dapat meningkatkan kinerja. Oleh karena itu, tujuan penelitian adalah untuk melihat bagaimana hubungan antara pengukuran kinerja non-finansial, job tension dan kinerja karyawan.

Penelitian ini memberikan kontribusi literatur mengenai penggunaan sistem pengukuran kinerja non-finansial dan dampaknya terhadap kinerja karyawan melalui job tension. Hall (2008) yang menunjukkan bahwa kelengkapan sistem pengukuran kinerja menyediakan informasi kinerja yang meningkatkan pemberdayaan psikologis manajer dan mengklasifikasikan peran manajer, yang pada gilirannya meningkatkan kinerja manajerial. Tanuwijaya \& Soenhadji (2009), yang menyimpulkan bahwa secara bersama-sama kemampuan karyawan, kesempatan berkinerja, kejelasan aturan dan penghargaan mempengaruhi kinerja karyawan. Diketahui bahwa semakin tinggi nilai kemampuan karyawan, kesempatan berkinerja, kejelasan aturan dan penghargaan, semakin tinggi pula kinerja karyawan yang dihasilkan. Sedangkan secara terpisah maka kemampuan karyawan tidak mempengaruhi kinerja karyawan. Selanjutnya hasil penelitian yang dilakukan oleh Lau dan Sholihin (2005) menyatakan bahwa pengukuran non-finansial mempengaruhi kepuasan kerja karyawan dan ukuran finansial tidak berpengaruh signifikan terhadap kepuasan kerja karyawan. Dengan demikian, studi ini kiranya dapat menambah pengetahuan tentang bagaimana sistem pengukuran kinerja non-finansial, job tension dan kinerja karyawan adalah saling terkait.

Selain itu, penelitian ini juga memberikan kontribusi dalam kaitannya dengan objek penelitian. Penelitian ini dilakukan di Institusi Kepolisian khususnya lingkungan Polda Lampung. Sholihin dan Pike (2010) meneliti tentang pengukuran kinerja keuangan maupun kinerja non-keuangan dan keadilan prosedural berpengaruh positif terhadap komitmen organisasi dan juga memiliki efek yang penting dalam hubungan interpersonal dan kerjasama dalam organisasi. Dengan demikian, penelitian ini memberikan kontribusi pada literatur tentang pengukuran non-finansial yang dilakukan di Institusi Kepolisian. Sehingga institusi kepolisian dapat menggunakan hasil penelitian ini sebagai bahan evaluasi bagi institusi kepolisian dalam melakukan kebijakan yang berkaitan dengan kinerja. Penelitian ini juga dapat digunakan sebagai masukan bagi Institusi Kepolisian untuk melihat manfaat penggunaan sistem pengukuran kinerja non-finansial terhadap peningkatan kinerja anggota kepolisian.

\section{KERANGKA TEORI DAN PENGEMBANGAN HIPOTESIS Sistem Pengukuran kinerja Non-Finansial}

Marshall et al (1999) mendefinisikan sistem pengukuran kinerja sebagai perkembangan indikator dan proses pengumpulan data yang dapat menjelaskan, melaporkan dan menganalisa sebuah kinerja. Sedangkan Neely et al (1995) melihat sistem pengukuran kinerja sebagai suatu proses untuk mengukur tindakan yang dilakukan dan secara spesifik mendefinisikan sistem pengukuran kinerja sebagai suatu proses untuk mengukur efisiensi dan efektivitas suatu tindakan. Sistem pengukuran kinerja dapat memberikan bukti bahwa pemahaman yang tinggi terhadap tujuan suatu pekerjaan, dapat 
memberikan informasi yang relevan terhadap pekerjaan, dan motivasi untuk meningkatkan kinerja suatu pekerjaan. Karena itu sistem pengukuran kinerja dianggap memiliki manfaat penting bagi perusahaan. Kim and Larry (1998) mengungkapkan sistem pengukuran kinerja merupakan frekuensi pengukuran kinerja pada manajer dalam unit oganisasi yang dipimpin mengenai kualitas dalam aktivitas operasional perusahaan. Dalam pengukuran kinerja perlu ditentukan apakah yang menjadi tujuan penilaian tersebut, apakah pengukuan kinerja tersebut untuk menilai hasil kerja (performance outcomes) ataukah menilai perilaku (personality). Menurut Han et al (1998) sistem pengukuran kinerja merupakan frekuensi pengukuran kinerja pada manajer dalam unit organisasi yang dipimpin mengenai kualitas dalam aktivitas operasional perusahaan.

Sholihin and Pike (2010) mengatakan bahwa sistem pengukuran kinerja menjadi pusat perhatian bagi akademisi maupun praktisi khususnya dibidang akuntansi manajemen. Sistem pengukuran kinerja mempunyai fungsi untuk mengevaluasi pencapaian tujuan organisasi (Chenhall, 2005, Kaplan and Norton, 1992, Kaplan and Norton, 1996. Jackson and Schuler (1985), dan Tubre and Collins (2000) menemukan bukti bahwa pemahaman yang tinggi terhadap tujuan suatu pekerjaan, dapat memberikan informasi yang relevan terhadap pekerjaan dan motivasi untuk meningkatkan kinerja suatu pekerjaan. Selain itu, sistem pengukuran kinerja dapat mengkomunikasikan prioritas organisasional dan informasi kinerja untuk setiap individu yang bisa membantu meningkatkan pemahaman manajer akan peran kerja mereka (Simon, 2000)

Cokins (2004) dalam Baxter and McLeod (2008) menyatakan bahwa untuk menentukan kinerja perlu dilakukan pengukuran kinerja. Pengukuran kinerja didefinisikan sebagai proses mengkuatifikasi efisiensi dan efektivitas dari suatu tindakan (Cocca and Alberti, 2010). Pengukuran kinerja adalah bagian dari analisa atau diagnosa terhadap proses untuk mengidentifikasi aktivitas mana yang harus diprioritaskan untuk diperbaiki agar mencapai hasil yang diinginkan. Dalam suatu organisasi pengukuran kinerja penting karena digunakan untuk mengukur evaluasi dan perencanaan masa depan suatu organisasi. Pengukuran kinerja merupakan suatu konsep mapan yang harus dilakukan dalam pembaharuan hal-hal penting dalam suatu organisasi. Untuk memenangkan persaingan global, sistem pengukuran yang hanya mempertimbangkan aspek keuangan semata tidak dapat mencerminkan kinerja manajemen sesungguhnya, sehingga diperlukan pengukuran yang tidak hanya mempertimbangkan ukuran-ukuran keuangan tetapi juga ukuran nonkeuangan.

Pengukuran kinerja organisasi perusahaan yang hanya ditekankan pada sudut pandang keuangan akan menghilangkan sudut pandang lain yaitu pengukuran kinerja nonkeuangan. Pengukuran kinerja non-keuangan dipercaya bisa digunakan untuk melengkapi figur pengukuran kinerja keuangan jangka pendek dan sebagai indikator kinerja jangka panjang (Kaplan dan Norton, 1996). Lau and Sholihin (2005) berargumen penggunaan pengukuran non-keuangan jangka panjang cenderung menghasilkan perilaku karyawan yang lebih positif dari pada yang dihasilkan oleh penggunaan pengukuran keuangan jangka pendek. Untuk melakukan pengukuran kinerja non-finansial terlebih dahulu kita harus mengetahui informasi-informasi non-finansial yang ada, karena informasi non-finansial merupakan salah satu faktor kunci untuk menetapkan strategi yang dipilih guna pelaksanaan tujuan yang telah ditetapkan. Informasi ini didapat agar dapat membantu dalam peningkatan pelaksanaan operasi perusahaan dan kinerja organisasi agar lebih berhasil. Informasi non-finansial menjadi penting karena dalam pendayagunaan karyawan tidak hanya difokuskan pada pengurangan biaya tenaga kerja, tetapi juga lebih kepada bagaimana meningkatkan kualitas, mengurangi siklus waktu produksi, dan kebutuhan pemuasan pelanggan. 


\section{Job Tension}

Stres berkaitan dengan tanggapan individu secara psikologis terhadap situasi atau peristiwa di lingkungan kerja, dapat berupa situasi atau peristiwa yang terlalu membebani seseorang baik secara fisik maupun psikologis. Stres yang terjadi dilingkungan kerja akan ditanggapi secara berbeda oleh setiap individu. Job tension dapat digunakan dalam memperjelas pengukuran stres. job tension juga dapat digunakan untuk menguji pengaruh stres di tempat kerja (Pool, 20oo). Dan ternyata didapat pengaruh yang berbeda, hal itu tergantung pada stres yang dialami oleh individu ditempat kerja (Macon, 1994).

Shields et al (200o) menyatakan bahwa job related stress berkaitan dengan tuntutan kinerja dan kemampuan kinerja. Sebagai tuntutan kinerja, job related stress berhubungan dengan ambiguitas peran (tugas ganda) dan tuntutan tugas yang melampaui kemampuan kinerja, sehingga ambiguitas peran akan mengurangi kinerja. Sebagai kemampuan kinerja, setiap individu tidak memiliki kemampuan yang pasti mengenai hasil pekerjaan atau bagaimana usaha untuk menyelesaikan tugas akan mempengaruhi hasil pekerjaan.

Job tension dapat berupa perasaan disfungsi pribadi yang diakibatkan oleh kondisi atau kejadian di tempat kerja, dan reaksi psikologis dan fisiologis karyawan yang disebabkan rasa tidak nyaman, tidak diinginkan atau ancaman di lingkungan kerja (Montgomery, 1996). Dunk (1993) menyatakan job-related tension akan berkaitan dengan hilangnya kreativitas dan keterlibatan kerja, dan berhubungan dengan peningkatan sifat antagonisme, ketidakhadiran dan pergantian karyawa. Ketika job tension mengganggu keseimbangan seseorang, maka perilaku individu akan menyimpang dari perilaku normal mereka yang pada akhirnya akan mempengaruhi hasil kinerja mereka.

Luthans, 2005, melakukan riset dibidang perilaku organisasi melaporkan bahwa stres dapat dikelompokkan dalam dua kategori yaitu distress dan eustrees. Distress berkenaan dengan stres yang dapat mengakibatkan turunnya kinerja, sedangkan eustrees berhubungan dengan stres yang pada tingkat tertentu (dari tingkatan nol hingga menengah) malah akan meningkatkan kinerja. Dari hasil penelitian tersebut diatas menunjukkan bahwa stres tidak hanya berpengaruh negatif terhadap kinerja, tetapi stres pada tingkat tertentu dapat pula berpengaruh positif terhadap kinerja.

\section{Pengembangan Hipotesis}

Sebelum kami mengusulkan hipotesis, kami meringkas research framework atas penelitian ini. Seperti di jelaskan diawal bahwa tujuan utama penelitian ini adalah untuk menguji apakah sistem pengukuran kinerja non-finansial dapat meningkatkan kinerja karyawan melalui job tension. Dari studi ini, kami menunjukkan bahwa job tension dapat memainkan peran mediasi dalam meningkatkan kinerja karyawan melalui sistem pengukuran kinerja non-finansial.

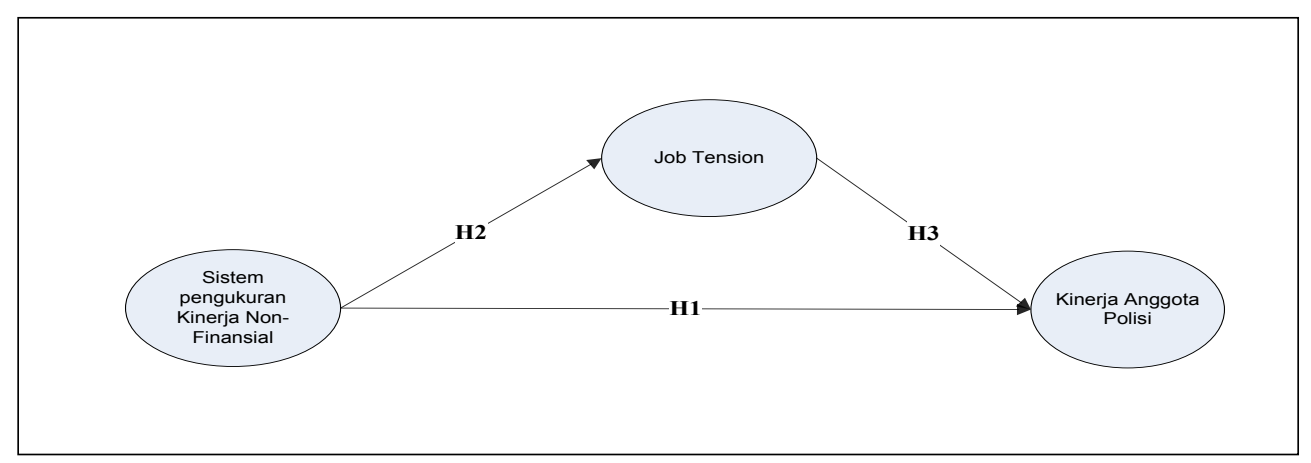

Gambar 1: Research framework hubungan pengukuran kinerja non-finansial, job tension terhadap kinerja karyawan. 


\section{Hubungan Sistem Pengukuran Kinerja Non-Finansial Terhadap Kinerja Anggota}

Sistem pengukuran kinerja dapat memberikan kejelasan tugas dengan memberikan pemahaman yang jelas kepada karyawan mengenai kinerja, dampak suatu tindakan, dan hubungan antar bagian yang berbeda dalam operasional perusahaan. Sehingga dapat dikatakan bahwa sistem pengukuran kinerja dapat memberikan informasi yang jelas kepada karyawan mengenai apa yang menjadi tanggung jawab kerjanya. Lawler (1992) berargumen bahwa informasi tentang misi suatu organisasi dan kinerja dibutuhkan untuk individu yang mengetahui bagaimana harus bertindak. Bowen and Lawler (1992) berpendapat bahwa informasi mengenai organisasi akan membuat seorang individu melihat lebih jelas dan memberikan pemahaman atas peranan mereka dalam perusahaan. Hal ini mengarah kepada hipotesis berikut:

H1: Sistem pengukuran kinerja non-finansial berpengaruh positif terhadap kinerja anggota.

\section{Hubungan Sistem Pengukuran Kinerja Non-Finansial Terhadap Job Tension.}

Pengukuran kinerja diharapkan dapat memberikan panduan yang jelas terhadap tujuan yang hendak dicapai individu dalam mendukung tujuan keseluruhan organisasi. Sehingga setiap individu mempunyai role clarity yang jelas atau tupoksinya. Salah satu contoh kejelasan role clarity adalah seperti yang dilakukan oleh Hall (2008) yang menemukan bahwa ada hubungan positif antara sistem pengukuran kinerja dengan role clarity. Aspek pertama pengukuran kinerja dapat mengurangi job tension dilihat dari kejelasan individu dari pekerjaan tersebut diatas sehingga dapat mengurangi role ambiguity. Burney et al (2009) mengatakan bahwa sistem pengukuran kinerja dapat mengurangi role ambiguity (Burney and widener, 2007) yang akhirnya dapat mengurangi job tension. Berdasarkan analogi tersebut, kami mengusulkan hipotesis 2:

H2: Sistem Pengukuran Kinerja berpengaruh negatif terhadap Job Tension.

\section{Hubungan Job Tension Terhadap Kinerja Anggota}

Tekanan kerja yang diterima oleh karyawan tentu akan memiliki pengaruh terhadap kinerja karyawan tersebut. Job tension merupakan bentuk tekanan mental dan fisik yang disebabkan adanya stres yang berhubungan dengan pekerjaan, dan hal ini tentu saja akan mempengaruhi kinerja individu dalam organisasi. Penelitian yang dilakukan oleh Lusch and Serpkenci (1990) menemukan pengukuran tekanan kerja akan menurunkan kinerja. Penelitian yang dilakukan oleh Pool (2000) menyatakan bahwa ada korelasi antara job tension dan kinerja, tingginya tekanan kerja akan menurunkan kadar kepuasan kerja, kinerja dan komitmen kerja. Shields et al (2000) menemukan terdapat korelasi negatif antara job related tension dan kinerja. Rogers et al (1993) dalam penelitiannya menyatakan jika job tension merupakan unsur dari stres, maka akan berhubungan dengan job outcomes. Jika tingkat job tension tinggi, maka akan mempengaruhi prestasi individu, perasaan pentingnya pekerjaan dan organisasi. Berdasarkan uraian diatas dapat diketahui bahwa tekanan kerja akan menurunkan kinerja dilihat dari tingginya tingkat tekanan kerja. Oleh karena itu, dalam penelitian ini kami menguji kembali hipotesis yang dipahami dalam literatur:

H3: job tension berpengaruh negatif terhadap kinerja anggota.

\section{METODE PENELITIAN}

\section{Pengumpulan Data}

Untuk menjawab tujuan penelitian, penulis menggunakan metode survei. Sedangkan sampel yang digunakan adalah institusi kepolisian di Provinsi Lampung. Penulis melakukan studi di kepolisian karena institusi kepolisian adalah institusi yang unik karena 
karakteristik anggota kepolisian itu berbeda dengan karakter pegawai pada umumnya. Hal ini dikarenakan struktur organisasi dikepolisian yang mempunyai sistem komando dan memiliki aturan-aturan tertentu. Hal ini didukung oleh (Metcalfe and Dick dalam Sholihin and Pike, 2010) yag mengatakan Institusi Kepolisian "Is a unique public service that relies on employee dedication in what is a turbulent, ambiguous and demanding role".

Dalam hal pengambilan sample di insituti kepolisian, sample yang kami pilih adalah anggota kepolisian yang berpangkat minimal briptu dan memiliki masa kerja minimal lima tahun. Hal ini dilakukan karena kami beranggapan bahwa sampel dengan kriteria demikian, sudah mengetahui mengenai sistem pengukuran kinerja dan sudah pernah diukur kinerjanya, serta sudah memahami kondisi organisasi. Sebelum kuesioner didistribusikan, kami melakukan pilot study untuk mengurangi bias atau kesalah pahaman, dan untuk memastikan bahwa terjemahan tidak mengubah arti dari isi kuesioner asli dan mereka memahami pertanyaan dengan baik. Penulis mendapatkan hasil validitas dan reabilitas yang baik dari pertanyaan dalam kuesioner. Penulis menyebarkan 165 set kuesioner dan kuesioner yang dikembalikan adalah 16o set kuesioner. Penulis menyebarkan kuesioner ke institusi kepolisian, yaitu Polda Lampung, Wilayah Polresta Bandarlampung, Polres Metro dan Wilayah Polres Lampung Selatan. Tehnik penyebaran kuesioner dilakukan dengan mengantar langung kemasing-masing Satker. Informasi demografis disajikan pada Tabel 1

Tabel 1. Demografi Responden

\begin{tabular}{|c|c|c|c|}
\hline Informasi Mengenai & Keterangan & Jumlah & $\%$ \\
\hline \multirow{2}{*}{ Jenis Kelamin } & Pria & 144 & $90 \%$ \\
\hline & Wanita & 16 & $10 \%$ \\
\hline \multicolumn{2}{|c|}{ Total } & 160 & $100 \%$ \\
\hline \multirow{4}{*}{ Usia } & $<30$ tahun & 38 & $23,75 \%$ \\
\hline & $31-40$ & 60 & $37,5 \%$ \\
\hline & $41-50$ & 36 & $22,5 \%$ \\
\hline & $>51$ & 26 & $16,25 \%$ \\
\hline \multicolumn{2}{|c|}{ Total } & 160 & $100 \%$ \\
\hline \multirow{3}{*}{ Pendidikan Terakhir } & SMA/Diploma & 94 & $58,75 \%$ \\
\hline & Sarjana $\left(\mathrm{S}_{1}\right)$ & 54 & $33,75 \%$ \\
\hline & $\mathrm{S}_{2} / \mathrm{S}_{3}$ & 12 & $7,5 \%$ \\
\hline \multicolumn{2}{|c|}{ Total } & 160 & $100 \%$ \\
\hline \multirow{6}{*}{ Divisi Kerja } & RESKRIM & 47 & $29,38 \%$ \\
\hline & SATLANTAS & 13 & $8,12 \%$ \\
\hline & SABHARA & 24 & $15 \%$ \\
\hline & INTELKAM & 19 & $11,87 \%$ \\
\hline & BINMAS & 17 & $10,63 \%$ \\
\hline & Lain-lain & 40 & $10,63 \%$ \\
\hline \multicolumn{2}{|c|}{ Total } & 160 & $100 \%$ \\
\hline
\end{tabular}

\section{Pengukuran Variabel}

\section{Sistem Pengukuran Kinerja Non-Finansial}

Kuesioner yang mengukur sistem pengukuran kinerja non-finansial menanyakan seberapa besar informasi tentang pengukuran kinerja non-finansial. Instrument dalam kuesioner ini diambil dari Ittner et al (2003) yang dikembangkan oleh Sholihin \& Pike (2010). Instrumen ini terdiri dari 9 pertanyaan. Dalam instrumen ini responden ditanya untuk mengetahui seberapa besar pendapat mereka tentang pertanyaan-pertanyaan 
tersebut dengan menggunakan 5 skala likert dimana point 1 menunjukkan skala sangat rendah dan point 5 menunjukkan skala sangat tinggi.

\section{Job Tension}

Job tension merupakan tekanan kerja yang dirasakan oleh karyawan dalam lingkungan kerjanya. Instrument dalam kuesioner job tension ini diambil dari Khan et al (1964) yang dikembangkan oleh Shields et al (2000). Instrumen job tension ini diukur dengan menggunakan 5 point skala likert. Responden ditanya seberapa besar pendapat mereka atas pertanyaan tersebut dengan menggunakan skala likert 1 sampai 5 , dimana point 1 menunjukkan skala sangat rendah dan point 5 menunjukkan skala sangat tinggi. Instrumen job tension ini terdiri dari 9 item.

\section{Kinerja Karyawan}

Kinerja dalam penelitian ini adalah kinerja karyawan sebagai kecakapan karyawan dalam melaksanakan kegiatan-kegiatannya. Kinerja adalah suatu prestasi yang dicapai oleh seseorang dalam melaksanakan tugas atau pekerjaannya sesuai dengan standar kriteria yang diterapkan dalam pekerjaan itu. Pengukuran kinerja non-finansial diharapkan akan mempengaruhi hasil kerja karyawan. Penggunaan pengukuran kinerja karyawan diukur menggunakan 5 point skala likert. Instrument ini diambil dari Burney and Widener (2007). Instrument kinerja karyawan ini terdiri dari 7 instrumen. Responden ditanya seberapa besar pendapat mereka atas pertanyaan tersebut dengan menggunakan skala likert 1 sampai dengan 5 , dimana point 1 menunjukkan skala sangat rendah dan point 5 menunjukkan skala sangat tinggi.

\section{HASIL DAN PEMBAHASAN}

Kami menggunakan Partial Least Square (PLS) untuk menguji model persamaan struktural. Partial Least Square (PLS) adalah model persamaan struktural (SEM) yang berbasis komponen atau variance yang tidak didasarkan pada banyak asumsi. Selain itu, Partial Least Square (PLS) juga dapat digunakan untuk memperjelas pengaruh antara variabel laten yang dibentuk dengan indikator refleksif dan formatif.

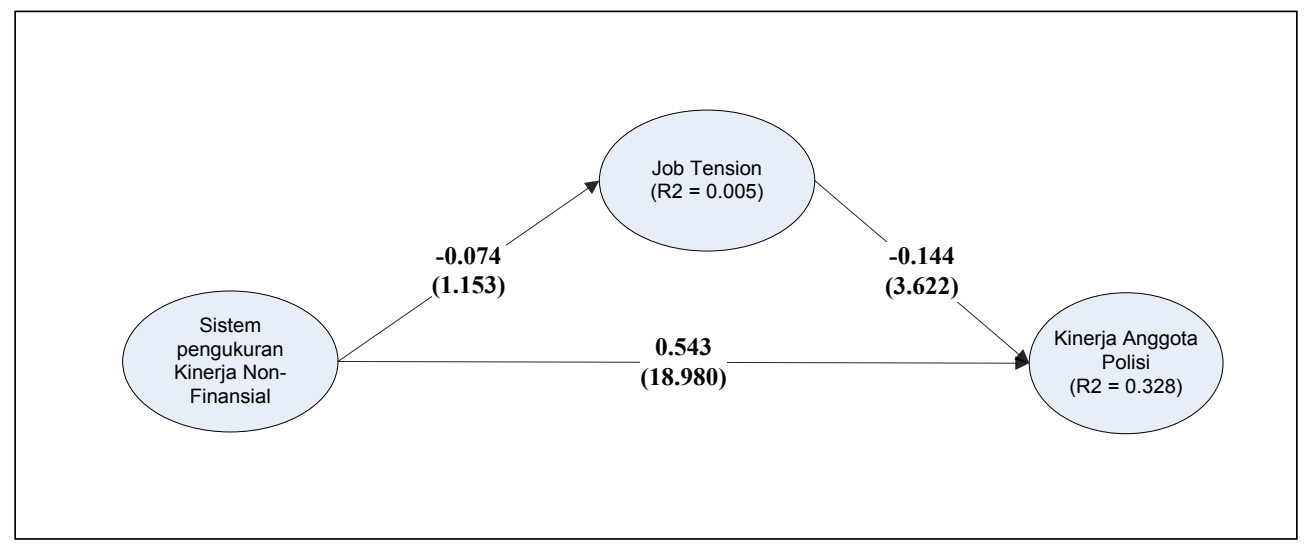

Gambar 2. Path Coefficient dan T-Hitung

Gambar diatas menjelaskan hubungan setiap konstruk dari masing-masing variabel dijelaskan oleh masing-masing indikator. Seperti yang telah dijelaskan sebelumnya bahwa Sistem pengukuran kinerja non-finansial, pertanyaan 1,3,6 dihilangkan (dieliminasi), demikian juga dengan indikator job tension, pertanyaan nomor 2,5,6 dan 9 dihilangkan (dieliminasi) dan untuk kinerja karyawan yang dihilangkan (dieliminasi) adalah pertanyaan nomor 7 karena korelasi konstruk tersebut tidak memenuhi kriteria convergent validity dimana nilainya kurang dari 0,5 . 


\section{Model Pengukuran}

Model pengukuran dinilai dengan menguji kedua validitas konvergen dan diskriminan. Validitas konvergen (Henseler, et, al, 2009) diuji menggunakan Average Variance Extracted (AVE). Henseler et al (2009) mengatakan bahwa nilai validitas convergent sangat baik apabila skor AVE diatas 0,5. Tabel 2 menunjukkan validitas konvergen yang sudah memadai, karena nilai AVE dari sebagian besar variabel lebih dari 0,5 dan satu variabel mendekati nilai 0,5 .

Tabel 2. Average Variance Extracted (AVE)

\begin{tabular}{|lc|}
\hline VARIABEL & AVE \\
\hline Sistem Pengukuran Kinerja Non-Finansial & 0,497 \\
Job Tension & 0,552 \\
Kinerja Karyawan & 0,520 \\
\hline
\end{tabular}

AVE tersebut juga dapat digunakan untuk menguji validitas diskriminan. Validitas diskriminan dapat uji dengan menggunakan dua metode, yaitu metode Fornell-Larcker dan metode Cross-loading. Metode Fornell-Larcker di lakukan dengan membandingkan square roots atas AVE dengan korelasi vertical laten. Validitas diskriminan memadai jika akar kuadrat dari AVE lebih tinggi dari korelasi Vertikal Laten. Tabel menunjukkan bahwa semua akar kuadrat dari AVE memiliki nilai lebih tinggi dibandingkan dengan nilai yang lainnya.

Pengujian Validitas Diskriminan dilakukan untuk melihat masing-masing item tidak sama dengan konstruk lain dalam model. Pengujian dilakukan dengan metode Cross Loading. Kriteria Cross Loading adalah masing-masing konstruk haruslah berkorelasi tinggi dibandingkan dengan konstruk yang lainnya (Al-Gahtani et al., 2007) seperti yang terdapat pada Tabel 3.

Tabel 3. Cross Loadings

\begin{tabular}{|c|c|c|c|c|}
\hline Variable & & PK & $\mathrm{JT}$ & KK \\
\hline \multirow{6}{*}{$\begin{array}{l}\text { Sistem Pengukuran } \\
\text { Kinerja Non-Finansial }\end{array}$} & $\mathrm{PK} 2$ & 0,668 & 0,045 & 0,372 \\
\hline & $\mathrm{PK}_{4}$ & 0,675 & 0,037 & 0,321 \\
\hline & PK 5 & 0,724 & $-0,023$ & 0,353 \\
\hline & $\mathrm{PK}_{7}$ & $\mathbf{0 , 7 0 1}$ & $-0,117$ & 0,325 \\
\hline & PK 8 & 0,708 & $-0,110$ & 0,513 \\
\hline & $\mathrm{PK}_{9}$ & $0,75^{2}$ & $-0,107$ & 0,396 \\
\hline \multirow[t]{5}{*}{ Job Tension } & $\mathrm{JT} 1$ & $-0,043$ & $\mathbf{0 , 7 7 5}$ & $-0,163$ \\
\hline & $\mathrm{JT}_{3}$ & 0,049 & 0,721 & $-0,118$ \\
\hline & $\mathrm{JT}_{4}$ & 0,004 & 0,706 & $-0,122$ \\
\hline & $\mathrm{JT} 7$ & $-0,156$ & $\mathbf{0 , 8 2 8}$ & $-0,165$ \\
\hline & JT 8 & $-0,026$ & $\mathbf{0 , 6 7 3}$ & $-0,082$ \\
\hline \multirow[t]{6}{*}{ Kinerja Karyawan } & $\mathrm{KK}_{1}$ & 0,364 & $-0,078$ & 0,665 \\
\hline & $\mathrm{KK} 2$ & 0,399 & $-0,153$ & 0,731 \\
\hline & $\mathrm{KK}_{3}$ & 0,390 & $-0,049$ & 0,745 \\
\hline & $\mathrm{KK}_{4}$ & 0,413 & $-0,158$ & 0,750 \\
\hline & $\mathrm{KK}_{5}$ & 0,405 & $-0,207$ & 0,663 \\
\hline & KK 6 & 0,418 & $-0,136$ & 0,764 \\
\hline
\end{tabular}


Model pengukuran juga dinilai dengan menguji reliabilitas per item. Pengujian reliabilitas menggunakan cronbach alpha dan composite reliability. Tabel 4 menunjukkan cronbach alpha dan composite reliability berkisar antara o,80o dan o,866. Oleh karena itu, nilai validitas dan reliabilitas adalah memadai.

Tabel 4. Cronbachs Alpha dan Composite reliability

\begin{tabular}{|l|c|c|}
\hline Variabel & $\begin{array}{c}\text { Composite } \\
\text { Reliability }\end{array}$ & $\begin{array}{c}\text { Cronbachs } \\
\text { Alpha }\end{array}$ \\
\hline Sistem Pengukuran Kinerja Non-Finansial & 0,856 & 0,800 \\
\hline Job Tension & 0,859 & 0,804 \\
\hline Kinerja Karyawan & 0,866 & 0,814 \\
\hline
\end{tabular}

\section{Penilaian Terhadap Model Persamaan Structural.}

Dalam penelitian ini, model struktural dinilai dengan cara $\mathrm{R}^{2}$ untuk variabel dependen dan uji koefisien jalur. Nilai $\mathrm{R}^{2}$ diatas o,1 dapat diterima (Camisón \& López, 2010). Gambar $2 \quad \mathrm{R}^{2}$ dari konstruk endogen lebih tinggi dari nilai minimum yang direkomendasikan. Selanjutnya, model structural diuji dengan koefisien jalur $(\beta)$ untuk memastikan hubungan antar konstruksi kuat. Kami menggunakan prosedur bootsrap dengan 500 penggantian (Hartman \& Slapnicar 2009). Sebuah hubungan yang kuat antara konstruksi terjadi jika koefisian jalur lebih tinggi dari o,10o (Urbach dan Ahlemann, 2010). Selanjutnya, koefisien jalur dianggap signifikan jika hubungan antara variable laten adalah pada tingkat 0,05. Dengan demikian, model structural dalam penelitian ini adalah memadai. Secara keseluruhan, model pengukuran dan penilaian model structural memuaskan. Langkah selanjutnya adalah pengujian hipotesis.

\section{Pengujian Hipotesis}

Hipotesis 1 menguji hubungan sistem pengukuran kinerja non-finansial dan kinerja anggota ( $\left.\mathrm{H}_{1}\right)$. Tabel 5 menunjukkan bahwa hubungan sistem pengukuran kinerja nonfinansial memiliki korelasi positif dan sangat signifikan dengan kinerja anggota $(\beta=0,534$, $\mathrm{t}=18,98 \mathrm{o}, \mathrm{p}<\mathrm{o}, \mathrm{ol})$ dan memiliki hubungan yang kuat. Dengan demikian Hipotesis $1\left(\mathrm{H}_{1}\right)$ terdukung oleh temuan ini. Hal ini menunjukkan bahwa adanya sistem pengukuran kinerja non-finansial akan meningkatkan kinerja karyawan. Hal ini sejalan dengan penelitian yang dilakukan oleh Lawler (1992) yang berargumen bahwa informasi tentang misi suatu organisasi dan kinerja dibutuhkan untuk individu yang mengetahui bagaimana harus bertindak. Bowen and Lawler (1992) berpendapat bahwa informasi mengenai organisasi akan membuat seorang individu melihat lebih jelas dan memberikan pemahaman atas peranan mereka dalam perusahaan.

Hipotesis 2 mengusulkan bahwa sistem pengukuran non-finansial secara negatif berkaitan dengan job tension. Temuan menunjukkan bahwa sistem pengukuran nonfinansial berpengaruh negatif dan lemah pada job tension $(\beta=-0,074, t=1,153, p<0,10)$. Dengan demikian Hipotesis 2 terdukung. Dari temuan ini dapat diketahui bahwa sistem pengukuran kinerja non-finansial akan menurunkan job tension. Hal ini sejalan dengan penelitian yang dilakukan oleh Buney et al (2009) mengatakan bahwa sistem pengukuran kinerja dapat mengurangi role ambiguity (Burney and widener, 2007) yang akhirnya dapat mengurangi job tension. 
Tabel 5. Pengukuran Struktural Model

\begin{tabular}{|c|c|c|c|}
\hline \multirow{2}{*}{$\begin{array}{c}\text { Variabel } \\
\text { Dependen }\end{array}$} & \multicolumn{2}{|c|}{ Variabel Independen } & \multirow{2}{*}{$\mathrm{R}^{2}$} \\
\cline { 2 - 3 } & $\mathrm{PK}$ & $\mathrm{JT}$ & \\
\hline \multirow{2}{*}{$\mathrm{JT}$} & $-0,074$ & & \\
\cline { 2 - 3 } & $1,153\left(^{*}\right)$ & & 0.005 \\
\hline \multirow{2}{*}{$\mathrm{KK}$} & 0,534 & $-0,144$ & \\
\cline { 2 - 3 } & $18,980\left(^{* * *}\right)$ & $3,622\left(^{* * *}\right)$ & 0.328 \\
\hline
\end{tabular}

Keterangan:

$(*) \quad$ : Tidak signifikan

$(* *) \quad$ : Signifikan

$(* * *) \quad$ : Sangat signifikan

Hipotesis 3 menyatakan bahwa ada hubungan negatif antara job tension dengan kinerja karyawan, table 5 menunjukkan bahwa job tension berpengaruh negatif dan sangat signifikan pada kinerja anggota $(\beta=-0,144, t=3,622, p<0,01)$. Dari temuan ini maka hipotesis 3 terdukung. Dari temuan ini dapat diketahui bahwa adanya job tension akan menurunkan kinerja anggota. Hal ini senada dengan penelitian yang dilakukan oleh Lusch and Serpkenci (1990), menemukan bahwa pengukuran tekanan kerja akan menurunkan kinerja. Penelitian yang dilakukan oleh Pool (2000) yang menyatakan bahwa ada korelasi antara job tension dan kinerja, tingginya tekanan kerja akan menurunkan kadar kepuasan kerja, kinerja dan komitmen kerja.

Tabel 6. Rangkuman Hasil Hipotesis

\begin{tabular}{|c|l|l|}
\hline $\begin{array}{l}\text { Hipotesi } \\
\mathbf{s}\end{array}$ & Deskripsi & Hasil \\
\hline $\mathbf{1}$ & $\begin{array}{l}\text { Sistem pengukuran kinerja non-finansial } \\
\text { berpengaruh positif terhadap kinerja } \\
\text { karyawan. }\end{array}$ & $\begin{array}{l}\text { Hipotesis } \\
\text { terdukung }\end{array}$ \\
\hline $\mathbf{2}$ & $\begin{array}{l}\text { Sistem pengukuran kinerja non-finansial } \\
\text { berpengaruh negative terhadap job tension }\end{array}$ & $\begin{array}{l}\text { Hipotesis } \\
\text { terdukung }\end{array}$ \\
\hline 3 & $\begin{array}{l}\text { Job tension berpengaruh negatif terhadap } \\
\text { kinerja karyawan }\end{array}$ & $\begin{array}{l}\text { Hipotesis } \\
\text { terdukung }\end{array}$ \\
\hline
\end{tabular}

\section{Analisis Jalur (Path Analysis)}

Pengujian analisis jalur dilakukan untuk menguji pengaruh tidak langsung variabel pengukuran kinerja (PK) terhadap kinerja karyawan (KK) melalui job tension (JT). Pengujian pertama dilakukan dengan menguji pengaruh job tension terhadap kinerja karyawan. Pengujian pengaruh mediasi dilakukan dengan menggunakan uji Sobel dengan alat hitung interaktif dari Preachers and Leonardelli (2003). Setelah melakukan perhitungan dengan menggunakan alat hitung interaktif dengan memasukkan nilai $\mathrm{PK} \rightarrow \mathrm{JT}(\mathrm{a})=-0,074$ dengan $\mathrm{Sa}=0,10$, dan nilai $\mathrm{JT} \rightarrow \mathrm{KK}(\mathrm{b})=0,144$ dengan $\mathrm{Sb}=0,01$ didapat $\mathrm{t}$ hitung $=0,739$. Berdasarkan hasil pengujian di atas, maka jika dibandingkan hubungan tidak langsung antara PK dengan KK melalui JT, yaitu 0,739, hubungan langsung antara PK dan KK yang mempunyai nilai jauh lebih besar yaitu $t=18,980$. Dengan demikian dapat disimpulkan bahwa pengukuran kinerja secara langsung dapat meningkat kinerja dibandingkann melalui job tension. 


\section{SIMPULAN}

Tujuan utama dari penelitian ini adalah untuk mencari pengaruh sistem pengukuran kinerja non-finansial pada peningkatan kinerja anggota melalui job tension. Responden dalam penelitian ini adalah anggota kepolisian yang bertugas di Polda Lampung, wilayah Polresta Bandarlampung, Polres Metro dan wilayah Polres Lampung Selatan, dengan kriteria anggota tersebut telah bekerja minimal 5 tahun dan berpangkat minimal Briptu. Dalam penelitian ini peneliti menyebar 165 kuesioner kepada responden, dan kuesioner yang kembali sebanyak 16o kuesioner. Data yang digunakan dalam penelitian ini adalah kuesioner yang di dapat dari 16o responden.

Dalam penelitian ini peneliti menggunakan SmartPLS untuk mengolah data yang digunakan, dan diketahui bahwa pengukuran kinerja non-finansial berpengaruh terhadap kinerja karyawan dengan melalui job tension. Dari analisa yang sudah dilakukan penulis, didapat hasil penelitian yaitu, hipotesis pertama terdukung, pengukuran kinerja nonfinansial berpengaruh positif terhadap kinerja karyawan. Hipotesis kedua sistem pengukuran kinerja non-finansial berpengaruh negatif terhadap job tension, hipotesis dua juga terdukung. Hipotesis ketiga terdukung dengan hasil signifikan job tension berpengaruh negatif terhadap kinerja anggota.

Berdasarkan hasil tersebut dapat disimpulkan bahwa dengan adanya pengukuran kinerja maka karyawan tersebut dapat bekerja lebih baik karena adanya kejelasan tupoksinya, dan dengan adanya kejelasan pekerjaan tersebut akan meningkatkan kinerja karyawan. Adanya sistem pengukuran kinerja non-finansial diharapkan dapat menurunkan job tension, karena sistem pengukuran kinerja dapat memberikan kejelasan tentang tugas kayawan berdasarkan tupoksi masing-masing dan hal tersebut dapat menurunkan tekanan kerja yang dialami oleh karyawan. Adanya penurunan job tension ini diharapkan dapat meningkatkan kinerja karyawan.

Penelitian ini memiliki keterbatasan yang dapat mempengaruhi hasil penelitian. Keterbatasan tersebut seperti yang telah dijelaskan sebelumnya bahwa penelitian ini dilakukan di instansi pemerintah (sektor publik) yaitu di institusi kepolisian. Oleh karena itu, generalisasi hasil penelitian ini, misalnya di organisasi yang berorientasi profit, harus dilakukan secara hati-hati.

Penelitian berikutnya dapat dilakukan dengan melakukan studi yang lebih luas terhadap instansi pemerintah yang lain diluar institusi kepolisian, atau dengan melakukan perbandingan kerangka penelitian ini antara institusi kepolisian dengan organisasi yag berorientasi profit. Penelitian berikutnya dapat melakukan perbandingan responden level karyawan dan level manajer.

Dengan bukti empiris diatas diharapkan dapat membawa implikasi terhadap Institusi Kepolisian, yaitu sebagai masukan bagi Institusi Kepolisian untuk melihat manfaat penggunaan pengukuran kinerja terhadap peningkatan kinerja anggota kepolisian.

\section{PUSTAKA ACUAN}

Al-Gahtani, S.S., Hubona, G.S., \& Wang, J. 2007. "Information Technology in Saudi Arabia: Culture and The Acceptance and Use of Information Technology". Information and Management, 681-191.

Baxter, L.F \& McLeod, A.M. 2008. "Managing Performance Improvement". New York: Routledge.

Bowen, D.E. and Lawler, E.E. 1992. "The empowerment of service workers: what, why, how, and when." Sloan Management Review, 33 (3) : 31-39. 
Burney, Laurie L., and Widener, S.K. 2007. "Strategic Performance Measurement Systems, Job-Relevant Information, and Managerial behavioral Responses-Role Stress and Performance". Behavioral Research in Accounting, 19:43-69.

Burney, L.L., Henle. C.A., Widener, S.K. 2009. "A Path Model Examining The Relations Among Strategic Performance Measurement System Characteristics, Organizational Justice, And Extra-and In-Role Performance". Accounting, Organizations and Society, $34(3-4): 305-321$.

Camisón, C. \& López, A.V. 2010. "An examination of the relationship between manufacturing flexibility and firm performance: The mediating role of innovation". International Journal of Operations \& Production Management. 30 (8) : 853-878.

Chenhall, Robert H. 2005. "Integrative Strategic Performance Measurement system, strategic alignment of manufacturing, learning and strategic outcomes: an exploratory study". Accounting, Organitations and Society, 30 (5):395-422.

Cocca, P \& Alberti, M. 2010. "A Framework to Assess Performance Measurement System in SMEs". International Journal of Productivity and Performance Management, 59 (2) : 186-200.

Dunk, A.S. 1993. "The Effects of Job-Related Tension On Managerial Performance In Participative Budgetary Settings". Accounting organizations and society.

Hall, Matthew. 2008. "The Effect of Comprehensive Performance Measurement System on Role Clarity, Psychological Empowerment and Managerial Performance". Accounting, Organizations and Society 33 (2-3): 141-163. Strategic Management Journal 20 (2): 195204.

Han, J.K., K. Namwoon, and R.K. Srivastava. 1998. "Market Orientation and Organizational Performance: Is Innovation A Missing Link?” Journal Of Marketing. 62 (4): 30-45.

Hartman, F., \& Slapnicar, S. 2009. "How Formal Performance Evaluation Effects Trust Between Superior and Subordinate Managers". Accounting, Organizations \& Society, 34 (6-7): 722-737.

Henseler, J., Ringle, C., Sinkovics, R. 2009. "The Use of Partial Least Squares Path Modeling in International Marketing". Advances In International Marketing, 20: 277-319.

Hoque, Z., James, W. 200o. "Linking Balanced Scorecard Measures To Size and Market Factor : Impact On Organizational Performance". Journal Of Management Accounting Research 12: 1-16.

Hoque, Z., Mia, L., Alam, M. 2001. "Market Competition, Computer-Aided Manufacturing and use Of Multiple Performance Measures: An Empirical Study". British Accounting Review 33: 23-45.

Ittner, C.D., D.F. Larcker and T Randall. 2003. "Performance Implications Of Strategic Performance Measurement In Financial Service Firm". Accounting, Organizations and Society $28: 715-41$.

Jackson, S.E. and Schuler, R.S. 1985. "A Meta-Analysis and Conceptual Critique Of research On role Ambiguity and Role Conflict In Work Settings." Organizational Behavior and Human Decision Processes. 36 : 16-78.

Kahn, R., Wolfe, D., Quinn, R., Snoek, J., and Rosenthal, R. 1964. "Organizational stress: studies in role conflict and ambiguity", New York: John Wiley.

Kaplan, R.S., and D.P. Norton. 1992. "The Scorecard: Measures That Drive Performance". Harvard Business Review 70: 71-79.

Kaplan, R.S. and Norton, D.P. 1996. "Translating Strategy Into Action: The Balanced Scorecard". Boston, Harvard Business School Press.

Kim, L and Larry, N. 1998. "Performance effect of complementarities between manufacturing practice and management accounting system". Journal of management accounting research 10: 325-346. 
Lau, C.M., \& Sholihin, M. 2005. "Financial and Nonfinancial Performance Measures: How do They Affect Job Satisfaction?.” The British Accounting Review, 37 : 389-413.

Lawler, E. E. 1992. "The Ultimate Advantage: Creating the High Involvement Organization". San Francisco, CA: Jossey-Bass.

Lusch, R.F \& Serpkenci, R.R. 1990. "Personal Differences, Job tension, Job Outcomes and Store Performance: A Study Of Retail Store Manager". Jurnal Of Marketing. 54 : 8-101.

Luthans, Fred. 2005. "Organizational Behavior". (1oth edition). New York: Mc Graw Hill Companies.

Macon, T. 1994. “Time Management Test o Process Model”, Journal Of Applied Psychology, 79 (3): 381-91.

Marshall, M., Wray, L., Epstein, P., and Grifel, S. 1999."21 century community focus: better result by linking citizens, government and performance measurement".Public Management, 81 (10) : 12-19.

Montgomery, D.C., Blod Gett, J.G. and Barnes, J.H. 1996. "A Model Of Financial Securities Sales Person's Job Stress", The Journal Of Service Marketing, 10 (3) : 21-34.

Neely, A., Gregory, M. and Platts, K. 1995. "Performance measurement system design: a literature review and research agenda". International Journal of Operations and Production Management, 15 (4): 80-116.

Pool, S.W. 2000. "Organizational Culture And Its Relationship Between Job Tension In Measuring Outcomes Among Business Executives". Journal Of Management Development. 19 (1): 32-49.

Preachers, K.J., \& Leonardelli, G.J. 2003. "Calculation For The Sobel Test". Retrieved May 6, 2014. From http://www.quatpsy.org/sobel/sobel.htm.

Rogers, J., Clo, K and Kash. T. 1993. "Increasing Job Satisfaction Of Service Personal”, Journal Of Service Marketing, 8 (1) : 14-28.

Shields, M.D., Deng. F.J., Kato, Y. 2000. "The Design and Effects Of Control Systems: Tests of Direct-and Indirect-Effects Models". Accounting, Organization and Society, 25: 185202.

Sholihin, M \& Pike, R. 2010. "Organizational Commitment in The Police Service: Exploring The Effects of Performances Measures, Procedural Justice, and Interpersonal Trust". Financial Accountability and Management, 26 (4):392-413.

Simons, R. 200o. "Performance Measurement \& Control Systems For Implementing Strategy: Text $\mathcal{E}$ Cases”. Upper Sadle River, Prentice Hall.

Tubre, T.C. and Collins, J.M. 200o. "Jackson and Schuler (1985) Revisited: A Meta-Analysis Of The Relationships Between Role Ambiguity, Role Conflict and Job Performance." Journal of Management 26(1): 155-169.

Urbach, N., \& Ahlemann, F. 2010. Structural Equation Modeling in Information System Research Using Partial Least Square. Journal of Information Technology Theory and Application, 11 (2): 5-39.

Yogaswara Achmad Tanuwijaya \& Imam Murtono Soenhadji, Ph.D. 2009. Pengaruh Kemampuan Karyawan, Kejelasan Aturan, Kesempatan Berkinerja \& Penghargaan Perusahaan Terhadap Kinerja Karyawan. Thesis. 